\title{
Fatal renal haemorrhage following haemodialysis in a patient with obstructive uropathy
}

\author{
R. PALANISWAMY* \\ M.S., M.Ch. \\ M. S. RAO \\ K. RAGHU \\ M.D.
}

\author{
P. C. SINGHAL \\ M.D., D.M. \\ D. S. LAIMAYUM \\ M.B., B.S. \\ K. S. N. CHARY \\ M.S., M.Ch.
} Departments of Urology, Nephrology and Pathology, Postgraduate Institute of Medical Education and Research,
Chandigarh 160012, India

\section{Summary}

A 22-year-old male with obstructive uropathy and renal failure was given pre-operative haemodialysis. He collapsed five hours later. Autopsy revealed massive intrarenal haemorrhage and rupture of a dilated superior calyx intraperitoneally. Anticoagulation employed during haemodialysis was probably responsible for this spontaneous renal haemorrhage and subsequent calyceal rupture.

KEY WORDS: renal failure, uropathy, haemodialysis, calyx, haemorrhage.

\section{Introduction}

Spontaneous haemorrhage into various anatomical regions in chronically haemodialysed patients is well documented (Leonard and Shapiro, 1976; Bhasin and Dana, 1978; Vanichayakornkul et al., 1974; Stewart et al., 1966; Alfrey et al., 1968). Such an incident resulting in fatal subdural haematoma (Leonard and Shapiro, 1976) or ovarian haemorrhage (Glass, Imrie and Gabriel, 1976) has been reported. This report represents perhaps the first case of intrarenal bleeding resulting in rupture of the superior calyx and haemoperitoneum following haemodialysis.

\section{Case report}

A 22-year-old male was admitted to the emergency urology service with oliguria of seven days duration. He had spontaneously passed many calculi per urethra since childhood but he did not seek urologi-

* Present address: School of Medical Sciences, Universiti Sains Malaysia, Pulau Pinang, Malaysia. cal advice for this problem. Two months before admission he suffered from severe right flank pain which he ignored. On physical examination, the right kidney was palpable, smooth and mildly tender. Respiratory, cardiovascular and neurological systems were unremarkable. Laboratory investigations showed haemoglobin $12.8 \mathrm{~g} / \mathrm{dl}$, a neutrophil polymorph leucocytosis, platelet count $310 \times 10^{4} /$ litre, blood urea $20 \mathrm{mmol} /$ litre, serum creatinine 822 $\mu \mathrm{mol} / \mathrm{litre}$. The bleeding time, clotting time and prothrombin time with kaolin were normal. Abdominal X-ray showed a large soft tissue shadow in the right upper abdomen with multiple radiopaque shadows in both renal areas (Fig. 1). Infusion pyelogram (Rao et al., 1978) revealed a hugely dilated right renal pelvis containing calculi. The left kidney was not visualized. He was given haemodialysis for $5 \mathrm{hr}$ with systemic heparinization, as preoperative preparation. Heparin (4,000 units) was administered intravenously at the onset of dialysis and 2,000 units after three hours. Intradialysis clotting time was maintained between 20 to $30 \mathrm{~min}$. At termination of dialysis the clotting time was $14 \mathrm{~min}$. Five hours after the dialysis he collapsed suddenly and resuscitative measures were unsuccessful.

Autopsy revealed two litres of blood in the peritoneal cavity. The right kidney (including calculi) weighed $750 \mathrm{~g}$ and showed rupture of the anterior wall of dilated superior calyx into the peritoneal cavity. The pelvicalyceal system was filled with clots and fluid blood in addition to the calculi (Fig. 2). The left kidney weighed $200 \mathrm{~g}$ and contained multiple calculi; it also showed scarring of the parenchyma. There was no evidence of bleeding into any other 


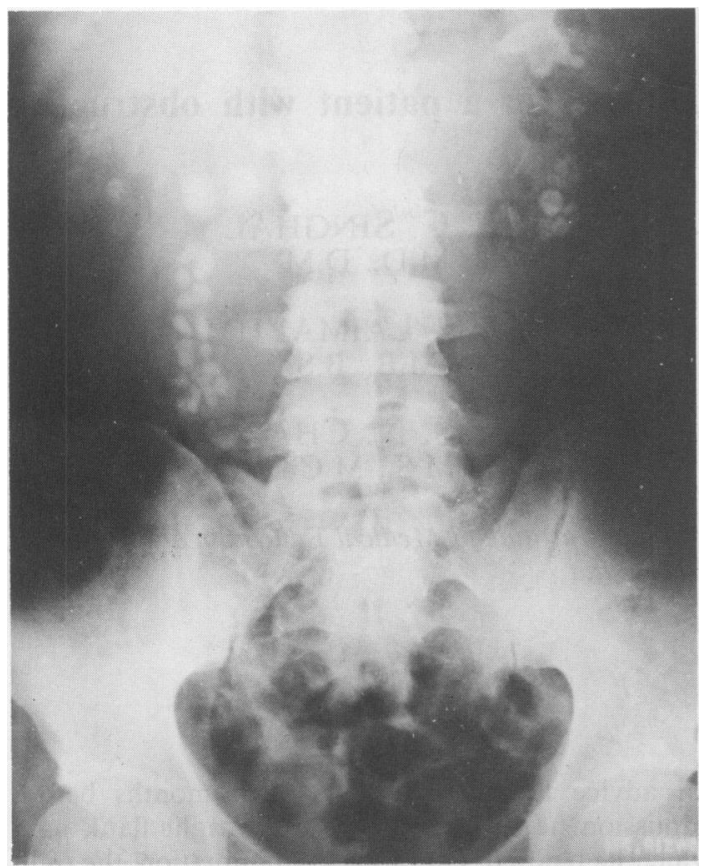

FIG. 1. X-ray of kidney, ureter and bladder shows a huge soft tissue shadow in the right upper abdomen. Multiple radiopaque shadows are seen in both renal areas.

major body cavity or tissue plane. Histology of the right kidney revealed features of chronic interstitial nephritis.

\section{Discussion}

As a large number of patients with chronic renal failure are enrolled in regular haemodialysis programmes, reports of bleeding into various parts of the body have been reported increasingly (Leonard and Shapiro, 1976; Bhasin and Dana, 1978; Vanichayakornkul et al., 1974; Stewart et al., 1966; Alfrey et al., 1968; Glass et al., 1976). Subdural haematoma, retroperitoneal haematoma, haematoma of the rectus abdominis, hyphaema, haemorrhagic pleural effusion, gastrointestinal bleeding, ovarian haemorrhage and haemopericardium are examples of such bleeds. Generalized clotting abnormality associated with systemic heparinization (Maher et al., 1963), oral anticoagulant therapy for maintenance of the vascular device patency and platelet dysfunction including thrombocytopaenia have been implicated (Bhasin and Dana, 1978).

Impacted calculi themselves can cause gross bleeding at times and this, enhanced by the anticoagulation, would have led to rupture of the obstructed

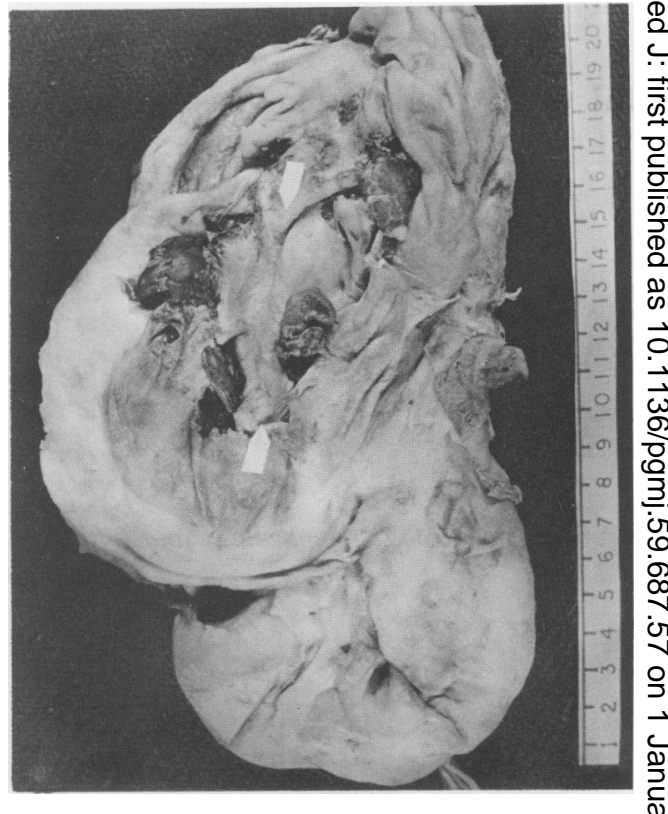

FIG. 2. Photograph of ruptured anterior surface of the superior ca稌 of right kidney. Arrows indicate the margins of the calyceal rupture. (The calculi and blood clots have been removed for claritg).

pelvicalyceal system in the present case. Haemosac dysfunction associated with non-dialysable proteins such as the Von Willebrand factor could ha/e contributed to the bleed in our patient. Maher apd associates (1963) discussed the importance of tegional heparinization for haemodialysis in patien who have potential for bleeding to reduce the chance of spontaneous haemorrhage. Rebound anticoagulattion in cases where regional heparinization was employed has been reported by Vanichayakornkuig్t al. (1974).

Spontaneous rupture of the renal pelvis has been reported following infusion pyelography ( $R$ ao et $a$, 1979). The contributing factors are sudden increase in intrapelvic pressure due to the diuresis induced by the urographic contrast in a partially obstructed pelvicalyceal system and diseased status of the ren pelvis. In such a situation, extravasation of contrast will be noticeable in the urogram. But at surgicyl exploration or autopsy, a perinephric urinoma will be found, and not massive intrarenal haemorrhage \&ि haemoperitoneum as in this case.

\section{References}

Alfrey, A.C., Gross, J.E., OGden, D.A., VoGel, J.H.K. \& Homé J.H. (1968) Uraemic haemopericardium. American Journal-of Medicine, 45, 391.

BHASIN, H.K. \& DANA, C.L. (1978) Spontaneous retroperitonegal 
haemorrhage in chronically haemodialysed patients. Nephron, 22, 322.

GlaSS, J., IMRIE, A. \& GabRIEL, R. (1976) Fatal ovarian haemorrhage associated with haemodialysis. British Medical Journal, 2, 1448 .

Kazatchinine, M., Sultan, Y., Caen, J.P. \& Bariety, J. (1976) Bleeding in renal failure: a possible cause. British Medical Journal, 2,612 .

LeONARD, A. \& ShapIRo, F.L. (1976) Subdural haematoma in regularly haemodialysed patients. Annals of Internal Medicine, 82, 1448.

Maher, J.F., Lapierre, L., Schreimer, G.E., Geiger, M. \& WESTER VELT, F.B. JR. (1963) Regional heparinization for haemodialysis. New England Journal of Medicine, 268, 451.

RaO, M.S., Bapna, B.C., Sodhi, J.S., DatTa, B.N., Reddy, M.J.,
RaO, K.M.K. \& Vaidyanathan, S. (1978) The value and limitations of infusion pyelography in anuric patients. Urologia Internationalis (Basel), 33, 422.

RaO, M.S., Bapna, B.C., Subudhi, C.L., RajendRan, L.J., Shrikhande, V.V., RAO, K.M.K. \& Vaidyanathan, S. (1979) Spontaneous rupture of renal pelvis during post obstructive diuresis. European Urology, 5, 214.

SteWart, J.H., Tuck Well, L.A., Sinnett, P.F., Edwards, K.D.G. \& WHYTE, H.M. (1966) Peritoneal haematoma and haemodialysis. A comparison of their morbidity and of the mortality suffered by dialysed patients. Quarterly Journal of Medicine, 35, 407.

Vanichayakornkul, S., Cioffi, R.F., Her Per, E., O’Connell, J.M.B. \& ShAlhoUB, R.J. (1974) Spontaneous retroperitoneal haematoma, a complication of haemodialysis. Journal of the American Medical Association, 230, 1164.

(Accepted 18 May 1982) 